Climate Change Expert Group

Paper No.2017(5)

\title{
Accounting for mitigation targets in Nationally Determined Contributions under the Paris Agreement
}

Christina Hood (IEA) and Carly Soo (OECD) 


\section{OECD/IEA CLIMATE CHANGE EXPERT GROUP PAPERS}

This series is designed to make available to a wider readership selected papers on climate change issues that have been prepared for the OECD/IEA Climate Change Expert Group (CCXG). The CCXG (formerly called the Annex I Expert Group) is a group of government delegates from OECD and other industrialised countries. The aim of the group is to promote dialogue and enhance understanding on technical issues in the international climate change negotiations. CCXG papers are developed in consultation with experts from a wide range of developed and developing countries, including those participating in the regular Global Forum on the Environment organised by the CCXG. The full papers are generally available only in English.

The opinions expressed in these papers are the sole responsibility of the author(s) and do not necessarily reflect the views of the OECD, the IEA or their member countries, or the endorsement of any approach described herein.

Comments on the series are welcome, and should be sent to:

OECD Environment Directorate, 2 rue André Pascal, 75775 PARIS CEDEX 16, France, or by e-mail to env.contact@oecd.org

OECD/IEA Climate Change Expert Group Papers are published on www.oecd.org/environment/cc/ccxg.htm

This document and any map included herein are without prejudice to the status of or sovereignty over any territory, to the delimitation of international frontiers and boundaries and to the name of any territory, city or area.

The statistical data for Israel are supplied by and under the responsibility of the relevant Israeli authorities. The use of such data by the OECD is without prejudice to the status of the Golan Heights, East Jerusalem and Israeli settlements in the West Bank under the terms of international law.

This document has been produced with the financial assistance of the European Union.

The views expressed herein can in no way be taken to reflect the official opinion of the European Union.

(C) Copyright OECD/IEA (2017)

You can copy, download or print OECD content for your own use, and you can include excerpts from OECD publications, databases and multimedia products in your own documents, presentations, blogs, websites and teaching materials, provided that suitable acknowledgement of OECD as source and copyright owner is given.

All requests for commercial use and translation rights should be submitted to rights@oecd.org

Applications for permission to reproduce or translate all or part of this material should be addressed to:

Head of Publications Service

OECD, 2 rue André-Pascal, 75775 Paris Cedex 16, France

or

IEA, 9 rue de la Fédération, 75739 Paris Cedex 15, France 


\section{Foreword}

This document was prepared by the OECD and IEA Secretariats in response to a request from the Climate Change Expert Group (CCXG) on the United Nations Framework Convention on Climate Change (UNFCCC). The Climate Change Expert Group oversees development of analytical papers for the purpose of providing useful and timely input to the climate change negotiations. These papers may also be useful to national policy-makers and other decision-makers. Authors work with the CCXG to develop these papers. However, the papers do not necessarily represent the views of the OECD or the IEA, nor are they intended to prejudge the views of countries participating in the CCXG. Rather, they are Secretariat information papers intended to inform Member countries, as well as the UNFCCC audience.

Members of the CCXG are those countries who are OECD members and/or who are listed in Annex I of the UNFCCC (as amended by the Conference of the Parties in 1997 and 2010). The Annex I Parties or countries referred to in this document are: Australia, Austria, Belarus, Belgium, Bulgaria, Canada, Croatia, Czech Republic, Denmark, the European Community, Estonia, Finland, France, Germany, Greece, Hungary, Iceland, Ireland, Italy, Japan, Latvia, Liechtenstein, Lithuania, Luxembourg, Malta, Monaco, the Netherlands, New Zealand, Norway, Poland, Portugal, Romania, the Russian Federation, Slovak Republic, Slovenia, Spain, Sweden, Switzerland, Turkey, Ukraine, the United Kingdom of Great Britain and Northern Ireland, and the United States of America. Korea, Mexico, Chile and Israel are also members of the CCXG. Where this document refers to "countries" or "governments", it is also intended to include "regional economic organisations”, if appropriate.

\section{Acknowledgements}

The authors would like to thank OECD and IEA colleagues Jane Ellis, Justine Garrett, Sara Moarif, Andrew Prag, Manasvini Vaidyula, and Lola Vallejo, as well as the delegations of the European Commission, Mexico, New Zealand, Norway, Sweden and Switzerland for helpful comments on a previous draft. Particular thanks go to Kelley Kizzier (Ireland) and Harald Winkler (University of Cape Town) for their inputs to the paper and for co-facilitating discussions at the CCXG Global Forum in September 2017 that contributed to this paper.

The Secretariat would like to thank Australia (Department of Foreign Affairs and Trade), Belgium (Federal Public Service Health, Food Chain Safety and Environment), the European Commission, Finland (Ministry of the Environment), France (Ministry of Foreign Affairs and International Development), Germany (Ministry for Environment, Nature, Conservation, Building and Nuclear Safety), Japan (Ministry of the Environment), Netherlands (Ministry of Infrastructure and Environment), New Zealand (Ministry for the Environment), Norway (Ministry of Climate and Environment), Republic of Korea (Korea Energy Economics Institute), Sweden (Environmental Protection Agency), and Switzerland (Federal Office for the Environment), for their direct funding of the CCXG in 2017, and the OECD and IEA for their in-kind support.

\section{Questions and comments should be sent to:}

Christina Hood

IEA/STO/ECC

31-35 Rue de la Fédération

75015 Paris

France

Email: christina.hood@iea.org

All OECD and IEA information papers for the Climate Change Expert Group on the UNFCCC can be downloaded from: www.oecd.org/environment/cc/ccxg.htm 


\begin{abstract}
Accounting for mitigation targets in Nationally Determined Contributions under the Paris Agreement

Accounting for Nationally Determined Contributions (NDCs) under the Paris Agreement is needed to allow Parties to track individual progress towards their own mitigation-related NDC targets, understand others' NDC targets and their progress toward them, and assess collective progress towards the long-term mitigation goal. This paper aims to assist Parties and stakeholders in framing thinking around the nature of accounting for mitigation targets given the diversity of target types in NDCs, and also to discuss how accounting guidance could be applied at various stages in the NDC cycle. It provides a summary and unpacking of the key accounting provisions under the Paris Agreement and Decision text, discusses the implications of the range of NDC target types, then discusses the particular issues of accounting for cooperative approaches and for the land sector. It then explores how accounting guidance may be applied within the NDC cycle.
\end{abstract}

JEL Classification: F53, O44, Q54, Q56, Q58

Keywords: accounting, mitigation, carbon pricing, climate change, UNFCCC

\title{
Résumé
}

Comptabilisation des objectifs d'atténuation inscrits dans les contributions déterminées au niveau national dans le cadre de l'Accord de Paris

Il est nécessaire de comptabiliser les contributions déterminées au niveau national (CDN), dans le cadre de l'Accord de Paris, pour permettre à chacune des Parties de mesurer où elle en est dans la réalisation de ses propres objectifs d'atténuation, inscrits dans ses CDN, de comprendre les objectifs des autres Parties et leurs progrès, et d'évaluer où nous en sommes collectivement dans la réalisation de l'objectif d'atténuation à long terme. Ce document vise à aider les Parties et les acteurs concernés à structurer leur réflexion sur la nature de la comptabilisation des objectifs d'atténuation, compte tenu de la diversité des objectifs répertoriés dans les $\mathrm{CDN}$, et aussi à déterminer comment les directives sur cette comptabilisation pourraient être appliquées aux différents stades du cycle des CDN. Il résume et démêle les principales dispositions relatives à la comptabilisation contenues dans la Décision et l'Accord de Paris, examine les implications de la diversité des types d'objectifs inscrits dans les CDN, et s'intéresse ensuite aux problèmes particuliers de comptabilisation dans les initiatives menées en coopération et dans le secteur de l'utilisation des terres. Il porte aussi sur la façon d'appliquer les directives sur la comptabilisation dans le cadre du cycle des CDN.

Classification JEL : F53, O44, Q54, Q56, Q58

Mots-clés : comptabilisation, atténuation, tarification du carbone, changement climatique, CCNUCC 


\section{Table of contents}

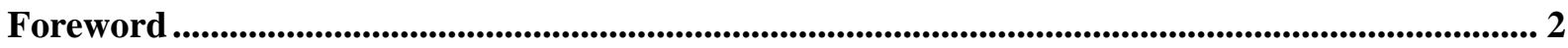

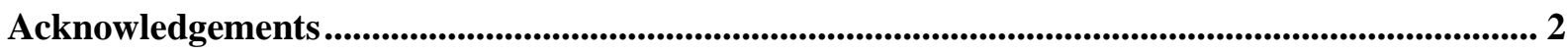

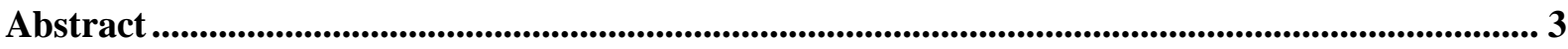

Résumé

List of acronyms ............................................................................................................................................ 5

1. Introduction .......................................................................................................................................... 6

2. Accounting in the context of the Paris Agreement ............................................................... 7

2.1. Unpacking key accounting-related elements in the Paris Agreement and Decision text.............. 7

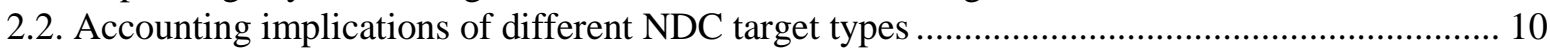

3. Accounting for co-operative approaches.............................................................................................. 16

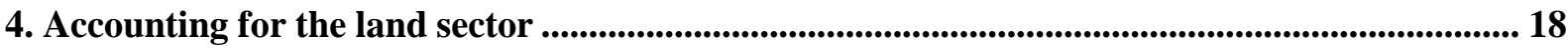

5. Application of accounting guidance within the NDC cycle................................................................. 20

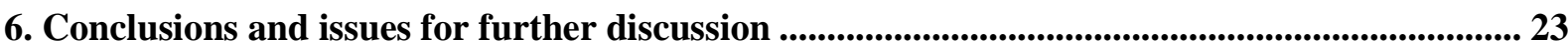

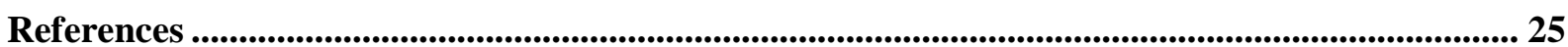

\section{Tables}

Table 1: Key elements of Paris Agreement and Decisions relevant to accounting ................................. 8

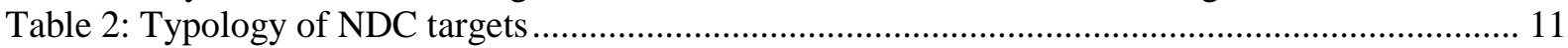

Table 3: Potential uses of accounting guidance by Parties for three example NDC target types.......... 22

Figures

Figure 1: Accounting combines information on emissions, ITMOs and land sector ............................ 13

Figure 2: A second example of accounting (for a different Party) ..................................................... 14

Figure 3: Use of accounting guidance at various stages in the first NDC cycle .................................. 21 
List of acronyms

\begin{tabular}{|l|l|}
\hline BAU & Business-as-usual \\
\hline CCXG & Climate Change Expert Group \\
\hline COP & Conference of the Parties to the UNFCCC \\
\hline CO $_{2}$-eq & Carbon dioxide equivalent \\
\hline CTU & Clarity, Transparency and Understanding \\
\hline GHG & Greenhouse Gas \\
\hline GDP & Gross Domestic Product \\
\hline GWh & Gigawatt-hours \\
\hline GWP & Global Warming Potential \\
\hline HWP & Harvested Wood Products \\
\hline IEA & International Energy Agency \\
\hline IPCC & Intergovernmental Panel on Climate Change \\
\hline ITMO & Internationally Transferred Mitigation Outcome \\
\hline LULUCF & Land use, Land Use Change, and Forestry \\
\hline MWh & Megawatt-hours \\
\hline NDC & Nationally Determined Contribution \\
\hline OECD & Organisation for Economic Co-operation and Development \\
\hline REDD+ & $\begin{array}{l}\text { Reducing emissions from Deforestation and forest Degradation in developing countries, and } \\
\text { the role of conservation, sustainable management of forests, and enhancement of forest }\end{array}$ \\
\hline SBSTA & Subsidiary Body for Scientific and Technological Advice \\
\hline TACCC & Transparency, Accuracy, Completeness, Consistency, Comparability \\
\hline UN & United Nations \\
\hline UNFCCC & United Nations Framework Convention on Climate Change \\
\hline
\end{tabular}




\section{Introduction}

1. In the context of the United Nations Framework Convention on Climate Change (UNFCCC), accounting refers to the processes for assessing progress towards, and achievement of, an emissions target (Prag, Hood and Barata, 2013 ${ }_{[1]}$; Hood, Briner and Rocha, 2014 ${ }_{[2]}$ ). The diversity of approaches used by Parties to express mitigation targets in their Nationally Determined Contributions (NDCs) under the Paris Agreement presents challenges in understanding, comparing and aggregating Party efforts. Accounting is needed to allow Parties to track individual progress towards their own mitigation-related NDC targets, understand others' NDC targets and their progress toward them, and assess collective progress towards the long-term mitigation goal. It is distinct from, but complementary to, the Paris Agreement's enhanced transparency provisions, which relate to the gathering, sharing and review of information.

2. The aim of this paper is to assist Parties and stakeholders in framing thinking around the nature of accounting for mitigation targets given the diversity of target types in NDCs, and also to discuss how accounting guidance could be applied at various stages in the NDC cycle. This paper compiles concepts relating to accounting for mitigation targets from previous CCXG papers and from documents prepared under the UNFCCC, including submissions from Parties prior to September 2017. It focuses on technical issues and is intended to serve as a primer for negotiators. An early draft of this paper informed discussions at the CCXG Global Forum in September 2017, with those discussions contributing to the final content of this paper.

3. This paper provides a summary and unpacking of the key accounting provisions under the Paris Agreement and Decision text (section 2.1), discusses the implications of the range of NDC target types (section 2.2) then discusses the particular issues of accounting for co-operative approaches (section 3) and for the land sector ${ }^{1}$ (section 4). It then explores how accounting guidance may be applied within the NDC cycle (section 5) and concludes by providing questions for further discussion.

\footnotetext{
${ }^{1}$ The term 'land sector' is used in this document as a generic term to cover forestry, land-use, and the land use, and land-use change and forestry (LULUCF). A number of NDCs include some or all of these land sector categories in their NDC mitigation target.
} 


\section{Accounting in the context of the Paris Agreement}

\subsection{Unpacking key accounting-related elements in the Paris Agreement and Decision text}

4. The Paris Agreement and its accompanying Decision (1/CP.21) include a number of elements relevant to accounting for mitigation targets (Table 1). Article 4.13 is the principal accounting provision, stating that Parties shall account for their NDCs, with some detail on its intended implementation provided in paragraphs 31-32 of the Decision text. Further accounting guidance (Decision 1/CP.21, paragraph 36) and rules modalities and procedures (Decision 1/CP.21, paragraph 37) are to be developed for those Parties choosing to participate in co-operative approaches under Article 6.2, or the new Article 6.4 mechanism. In order to undertake accounting, various pieces of information will be needed, including those provided for clarity, transparency and understanding at the time NDCs are communicated (Article 4.8), and information provided through the enhanced transparency framework, including national greenhouse gas (GHG) inventories (Article 13.7(a)).

5. The focus of Article 13.7(b) on information to track progress and achievement implies that the Paris Agreement's transparency framework could be the main vehicle for reporting and reviewing the accounting that Parties undertake. This view was echoed in submissions from Parties to the UNFCCC in April 2017, who saw accounting being included in the biennial communications and reviews of the enhanced transparency framework, rather than a separate process for accounting being established. Submissions from Parties were generally consistent in their understanding of the high-level role of accounting, seeing it as tracking progress towards and assessing achievement of NDCs, with many Parties adding that accounting is therefore essential in building trust and confidence (UNFCCC, 2017 $[3]$ ).

6. Most Parties have put forward NDCs that contain one or more quantitative mitigation targets (in terms of GHG levels or in other metrics), so accounting for these targets will necessarily involve a quantitative process. However Decision paragraphs 31(c) and 31(d) also suggest a broader interpretation of what it could mean to "account for" an NDC: here the focus is not on assessing achievement of the NDC target, rather it is on Parties providing a good explanation of their NDC's coverage, consistent with the standard of completeness (but in the context of national determination of NDCs). It remains an open question how far this broader meaning of "account for" (as "give an explanation of" ") might be developed in the accounting guidance. For example, in submissions (UNFCCC, $2017_{[3]}$ ) some Parties saw reporting on policy implementation progress as part of accounting, whereas others see accounting as referring more narrowly to quantitative elements. The broader concept of accounting could be particularly relevant for those Parties that have NDCs without quantitative mitigation targets, for example, implementation of policies or specific projects.

\footnotetext{
2 The Oxford Dictionaries provide a relevant definition of "account for" as to "Give a satisfactory record of (something, typically money, that one is responsible for).”
} 
Table 1: Key elements of Paris Agreement and Decisions relevant to accounting

\begin{tabular}{l} 
Paris Agreement \\
\hline Accounting for NDCs \\
Article 4.13: Parties shall account for their nationally determined \\
contributions. In accounting for anthropogenic emissions and \\
removals corresponding to their nationally determined contributions, \\
Parties shall promote environmental integrity, transparency, \\
accuracy, completeness, comparability and consistency, and ensure \\
the avoidance of double counting, in accordance with guidance \\
adopted by the Conference of the Parties serving as the meeting of \\
the Parties to this Agreement.
\end{tabular}
the Parties to this Agreement.

\section{Paragraph 31: Requests the Ad Hoc Working Group on the Paris Agreement to elaborate, drawing from approaches established under the Convention and its related legal instruments as appropriate, guidance for accounting for Parties' nationally determined contributions [...] which ensures that:}

(a) Parties account for anthropogenic emissions and removals in accordance with methodologies and common metrics assessed by the Intergovernmental Panel on Climate Change and adopted by the Conference of the Parties serving as the meeting of the Parties to the Paris Agreement;

(b) Parties ensure methodological consistency, including on baselines, between the communication and implementation of nationally determined contributions;

(c) Parties strive to include all categories of anthropogenic emissions or removals in their nationally determined contributions and, once a source, sink or activity is included, continue to include it;

(d) Parties shall provide an explanation of why any categories of anthropogenic emissions or removals are excluded;

Paragraph 32: Decides that Parties shall apply the guidance referred to in paragraph 31 above to the second and subsequent nationally determined contributions and that Parties may elect to apply such guidance to their first nationally determined contribution;

\section{Communication of NDCs}

Article 4.8: In communicating their nationally determined contributions, all Parties shall provide the information necessary for clarity, transparency and understanding [...].

Tracking progress towards NDCs / the enhanced transparency framework

Article 13.7: Each Party shall regularly provide the following information:

(a) A national inventory report of anthropogenic emissions by sources and removals by sinks of greenhouse gases, prepared using good practice methodologies accepted by the Intergovernmental Panel on Climate Change and agreed upon by the Conference of the Parties serving as the meeting of the Parties to this Agreement; and (b) Information necessary to track progress made in implementing and achieving its nationally determined contribution under Article 4 .

Article 13.11: Information submitted by each Party under paragraphs 7 and 9 of this Article shall undergo a technical expert review, in accordance with decision 1/CP.21. [...]

\section{Use of co-operative approaches}

Article 6.2: Parties shall, where engaging on a voluntary basis in cooperative approaches that involve the use of internationally transferred mitigation outcomes towards nationally determined contributions, [...] shall apply robust accounting to ensure, inter alia, the avoidance of double counting, consistent with guidance adopted by the Conference of the Parties serving as the meeting of the Parties to this Agreement.

Article 6.5: Emission reductions resulting from the mechanism referred to in paragraph 4 of this Article shall not be used to demonstrate achievement of the host Party's Nationally Determined Contribution if used by another Party to demonstrate achievement of its Nationally Determined Contribution.
[Paragraphs 27-28 provide further implementation guidance]

[Paragraphs 91-98 provide further implementation guidance]
Paragraph 36: Requests the Subsidiary Body for Scientific and Technological Advice to develop and recommend the guidance [...], including guidance to ensure that double counting is avoided on the basis of a corresponding adjustment by Parties for both anthropogenic emissions by sources and removals by sinks covered by their nationally determined contributions under the Agreement;

Paragraph 37: Recommends that the Conference of the Parties serving as the meeting of the Parties to the Paris Agreement adopt rules, modalities and procedures for the mechanism established by Article 6 , paragraph 4, of the Agreement 
7. In addition to the terms "account for" and "accounting," some Parties have used the terms "accountable" or "accountability" in the context of the Paris Agreement to describe a Party's obligation to explain or answer to other Parties regarding their performance in implementing and achieving their NDC. Under Article 13.7 (b) each Party must regularly provide information necessary to track progress it has made in implementing and achieving its NDC under Article 4. Each Party is also required to participate in technical expert review under Article 13.12 and the multilateral consideration of progress under Article 13.11 in which the implementation and achievement of its NDC will be reviewed and considered. It is important to stress that being "accountable" for implementing and achieving an NDC through this reporting and review process is not the same as being legally responsible for meeting an NDC target. Neither Article 13 nor Article 15, which establishes a non-punitive mechanism to facilitate implementation and promote compliance, has the mandate to impose penalties for non-performance or non-compliance with the Paris Agreement.

8. Article 4.13 refers to the "TACCC" elements in relation to accounting for the greenhouse gas emission and removals corresponding to the NDC target, as well as promotion of environmental integrity and avoidance of double counting. The meanings of the TACCC elements are already well established in Intergovernmental Panel on Climate Change (IPCC) and UNFCCC guidance for national greenhouse emissions inventories (IPCC, 2006 ${ }_{[5]}$ ):

- Transparency means that assumptions and methodologies are clearly explained and documented to facilitate replication and assessment

- Accuracy is a relative measure of the exactness of an estimate, which should not be systematically over or under the actual level, and uncertainties should be reduced as far as possible

- Completeness (in the context of national inventories) means that there is full coverage of sources, sinks, and gases in the IPCCC guidelines, across all geographic areas

- Comparability means that estimates should be comparable among Parties, through use of agreed methodologies and formats, including IPCC guidelines

- Consistency refers to coherence across time, with estimates using the same methodologies and data sets in the base year and subsequent years, and any updates applying across all years.

9. Article 4.13 also states that Parties shall promote environmental integrity and ensure avoidance of double counting. These standards are echoed in Article 6 with respect to accounting for co-operative approaches, and also in Decision 1/CP.21 (paragraph 92) that guides implementation of the enhanced transparency framework. Avoidance of double counting implies that emission reductions are not counted by more than one Party toward an NDC target, a critical issue for co-operative approaches under Article 6. It could also have a wider interpretation under Article 4, including avoiding double counting between emission outcomes claimed under the UNFCCC and those within the Carbon Offsetting and Reduction Scheme for International Aviation (CORSIA) system, or the avoidance of double-counting between mitigation and finance outcomes. There is no agreed definition of environmental integrity, but it encompasses the idea that reported results reflect genuine environmental gains. For example, in the context of carbon markets, one interpretation is that the transfer of units does not result in higher global emissions than would have occurred if NDCs were achieved domestically (SEI, 2016 $\left.6_{[6]}\right)$. 
10. Decision1/CP.21, paragraph 32 decides that Parties shall apply guidance for accounting from their second and subsequent NDC, although Parties may also choose to apply such guidance to their first NDC. Many Parties have NDCs with a 2030 target year, which could imply that accounting guidance would not need to apply until after that time. Alternatively the "first NDC" could be interpreted as the first of the ongoing series of five-yearly NDC communications, so the next five-yearly revision would constitute the "second NDC", implying an earlier coverage of the accounting guidance. The guidance (paragraph 36) and rules, modalities and procedures (paragraph 37) in relation to Article 6 co-operative approaches would apply for the first NDCs.

\subsection{Accounting implications of different NDC target types}

11. While Parties' NDC mitigation target types are nationally determined, Article 4.4 of the Paris Agreement does provide some direction regarding the form of these targets. This Article states that developed country Parties should undertake economy-wide absolute emission reduction targets, and encourages developing country Parties to move over time towards economy-wide emission reduction or limitation targets in light of different national circumstances. The current diversity of NDC target types could therefore be seen as a starting point, with convergence toward economy-wide emission targets expected over time in subsequent NDCs. Accounting guidance will need to address both the current diversity of NDC mitigation target types, while also supporting the direction signaled in Article 4.4.

12. While it would be theoretically possible to convert the current range of diverse NDC targets into a common accounting format ${ }^{3}$ (as in the Kyoto Protocol), in submissions no Parties proposed this type of "conversion" as a way forward for accounting under the Paris Agreement: rather submissions stressed the importance of respecting the nationally-determined nature of NDCs in the way that accounting guidance is developed (UNFCCC, 2017 ${ }_{[3]}$ ).

13. (Briner and Moarif, 2016 $[7]$ ) identified a series of NDC target types related to mitigation: these are arranged in the table below according to how the targets are quantified (and hence how they could be assessed) and by their sectoral coverage (Table 2). Targets referenced to a business as usual (BAU) baseline are the most common type of NDC target: over half of the NDCs submitted (UNFCCC, 2015b $\mathrm{b}_{[8]}$ ) include a target to reduce GHG emissions below a BAU baseline, either across the entire economy or for specific sectors (e.g. Type D or E, indicated by the red dashed outline in the Table below).

14. A number of Parties have multiple targets of different types within their NDC (for example a GHG intensity target and a renewable energy target). One possibility in accounting for NDCs with multiple targets would be for the Party to first clarify whether they intend all the targets to have equal status, or whether they wish to nominate a "principal” target that they would intend to be tracked and assessed. If Parties wish to have multiple targets, then these would all be accounted for.

\footnotetext{
${ }^{3}$ This would at least be theoretically possible for NDC targets that are expressed in quantitative terms.
} 
Table 2: Typology of NDC targets

\begin{tabular}{|c|c|c|}
\hline & Economy-wide coverage & $\begin{array}{l}\text { Less than economy-wide coverage (in terms of } \\
\text { sectors or gases) }\end{array}$ \\
\hline $\begin{array}{l}\text { Target quantified in } \\
\text { absolute GHG terms } \\
\text { ex ante (before } \\
\text { implementation) }\end{array}$ & $\begin{array}{l}\text { Type A: Economy-wide absolute emission } \\
\text { reduction targets }\left(\mathrm{tCO}_{2} \text {-eq) including }\right. \\
\text { achievement of carbon neutrality }\end{array}$ & $\begin{array}{l}\text { Type } \mathrm{B} \text { : Non-economy-wide absolute emission } \\
\text { reduction targets }\left(\mathrm{tCO}_{2} \text {-eq) }\right.\end{array}$ \\
\hline $\begin{array}{l}\text { Target can be } \\
\text { quantified in absolute }\end{array}$ & $\begin{array}{l}\text { Type D: Economy-wide goals to reduce } \\
\text { emissions relative to a BAU baseline ( } \mathrm{tCO}_{2} \text {-eq) }\end{array}$ & $\begin{array}{l}\text { Type E: Sector-specific goals relative to a } \mathrm{BAU} \\
\text { baseline (tCO }{ }_{2} \text {-eq) }\end{array}$ \\
\hline $\begin{array}{l}\text { GHG terms ex-post } \\
\text { (and estimated ex- } \\
\text { ante) }\end{array}$ & $\begin{array}{l}\text { Type F: Emissions intensity goals ( } \mathrm{kgCO}_{2} \text {-eq per } \\
\text { unit of GDP); Emissions per capita goals ( } \mathrm{tCO}_{2-} \\
\text { eq per cap) }\end{array}$ & 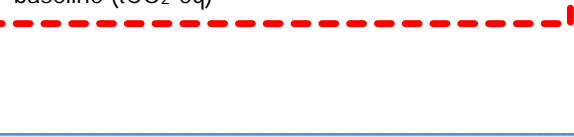 \\
\hline $\begin{array}{l}\text { Target quantified in a } \\
\text { non-GHG metric }\end{array}$ & & $\begin{array}{l}\text { Type G: Various non-GHG goals, including for non- } \\
\text { fossil or renewable energy, energy efficiency, forest } \\
\text { cover, etc. }\end{array}$ \\
\hline $\begin{array}{l}\text { Targets that would } \\
\text { require other } \\
\text { indicators of } \\
\text { progress/achievement }\end{array}$ & $\begin{array}{l}\text { Type C: Peaking emissions in a given year } \\
\text { (limited sectors or gases) }\end{array}$ & $\begin{array}{l}\text { Type } \mathrm{H} \text { : Implementation of qualitative policies and } \\
\text { measures, creation of institutions etc. }\end{array}$ \\
\hline Non quantified goal & Type I: No measurable goals & \\
\hline
\end{tabular}

Note: The red rectangle denotes the most common NDC types expressed by Parties

Source: Adapted from Briner \& Moarif (2016)

15. It may be possible to deal with some elements of accounting guidance in a generic manner. That is, the elements of Article 4.13 (TACCC, environmental integrity, avoidance of double counting) could have implications that are shared among all quantitative NDC targets. For example, the standard of consistency would suggest that the same methodologies and data sources should be used in their base year, during implementation, and in the target year for definition of the target, demonstration of progress, and assessment of achievement. ${ }^{4}$ The standard of transparency suggests that the methodologies to be used to assess progress and achievement should be clearly understood by a third Party, for example that Parties clarify what indicators or milestones will be used to assess progress in achieving the NDC target.

16. Generic guidance that lacks specificity could however create significant challenges for Parties in knowing exactly how to conduct the accounting, and for review of accounting information (explored in more detail in (Vallejo, 2017[9])). If guidance remains at the level of general principles, these could be interpreted differently by individual reviewers and Parties, leading to inconsistent outcomes from reviews. The diversity of NDC target types also suggests that the accounting guidance may need to have some elements that are applicable to particular NDC target types and not others, in addition to the generic elements.

17. There is significant experience in Annex I Parties to the Kyoto Protocol with accounting for absolute economy-wide multi-year emission reduction or limitation targets. This is relevant for those Parties with absolute NDC targets, and may become

\footnotetext{
${ }^{4}$ For example if a Party improves its inventory procedures to a higher tier or to follow newer IPCC guidance, the base-year inventory would also need to be updated. This could also have implications for NDC targets referenced to the base year: in the Kyoto Protocol targets were fixed with issuance of Assigned Amount, but the Paris Agreement could take a different approach of allowing technical updates if base-year parameters change.
} 
more relevant over time if more Parties adopt economy-wide emission reduction or limitation targets in subsequent NDCs.

18. For targets expressed as a quantity of GHG emissions (types A, B, D, E, F as outlined in Table 2 above), the starting point of tracking progress would be to compare the national GHG inventory emissions with the target GHG levels to provide an understanding of progress towards (during implementation) and achievement of the target (after the end of the period). Use of co-operative approaches (under Article 6) and accounting for the land sector add further steps to the accounting process. International transfers of mitigation outcomes (ITMOs) will lead to additions or subtractions to correctly attribute transfers between Parties, as discussed in section 3 below. As will be discussed in section 4, the land sector is often accounted for in a different way toward mitigation targets than is reflected in the national inventory: for example in the Kyoto Protocol and REDD $+{ }^{5}$ frameworks a forward-looking baseline may be used as a reference against which change is accounted for. The seemingly straight-forward comparison of emissions with a target level still requires a number of details to be clarified, for example:

- Parties with sectoral GHG targets, or targets that only cover a certain number of gases would need to clarify which parts of the national inventory are covered by the NDC target, so that comparison of emissions only in the relevant sector against target levels can be made.

- In order to track progress during implementation with NDC targets that are expressed relative to a baseline (BAU, intensity or per capita targets), an estimate of the target emissions level would be needed ex ante (before implementation). Methodological consistency (1/CP.21 para 31 (b)) implies that the same method and data sources be used to calculate this ex ante estimate as are used for calculating the final target level, once the actual target-year parameters (GDP, population etc.) are known. Transparency would be important regarding the data used, methods for estimating and calculating the target, and any process for revising estimates of the target.

- The guidance could address how technical corrections (e.g. use of updated inventory methodologies for base and target years) affect target levels or baselines, to support continuous improvement of methodologies and processes while maintaining clarity.

19. The accounting guidance could specify the process for how inventory emissions should be compared to the target level, after accounting for ITMOs and the land sector. Figure 1 shows an example of a Party that exports ITMOs corresponding to some of the emissions reductions (mitigation outcomes) that it has achieved in the target year/period (Figure 1(a)). Figure 1(b) shows how the emissions inventory could be combined with information on ITMO transfers and land sector (in this case, net sequestration from forestry) to create an "accounting balance" (Prag, Hood and Barata, 2013 ${ }_{[1]}$ ). In this example, the export of ITMOs would be reflected as an addition, and net sequestration from the land sector by a subtraction. 6 The accounting balance can then be compared to

\footnotetext{
${ }^{5}$ Reducing emissions from deforestation and forest degradation in developing countries, and the role of conservation, sustainable management of forests, and enhancement of forest stocks.

${ }^{6}$ For Parties that are net importers of ITMOs, the ITMO use would conversely result in a subtraction starting from inventory emissions. For Parties in which land sector emissions result in net emissions rather than net sequestration, there would be an addition rather than a subtraction.
} 
the target level to assess achievement of the NDC target: the final result in this example is that the Party has over-achieved its NDC target. At no stage is the actual emissions inventory itself altered or adjusted: this process relates to calculation of the "accounting balance”.

Figure 1: Accounting combines information on emissions, ITMOs and land sector

(a)

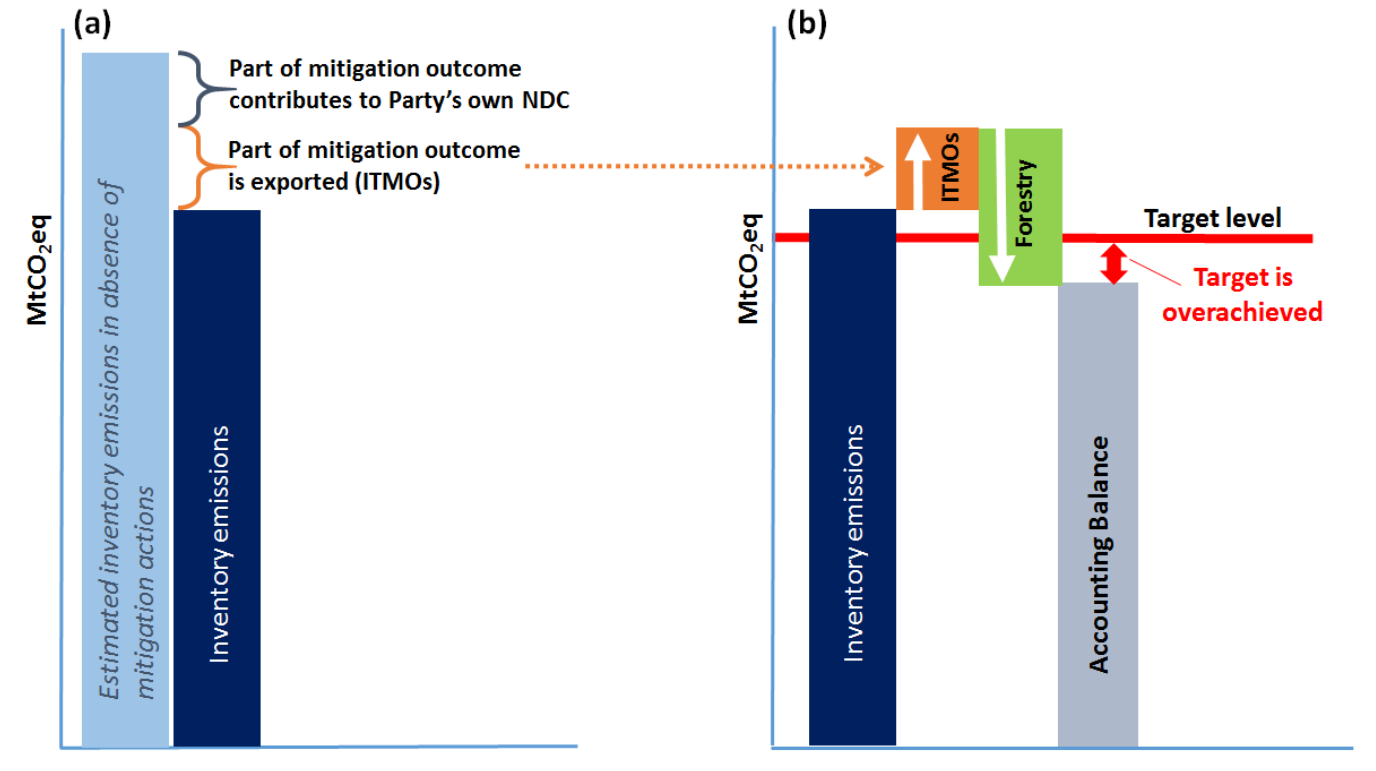

Source: Adapted from Prag, Hood, and Barata (2013)

20. A second example (Figure 2) shows a different Party that has net emissions in the land sector (e.g. increasing deforestation), and is a net importer of ITMOs which it uses towards its NDC. Here, the land sector emissions would be an addition, the use of ITMOs a subtraction. In this example, the Party has purchased and used the precise quantity of ITMOs needed to meet its NDC target exactly. 
Figure 2: A second example of accounting (for a different Party)

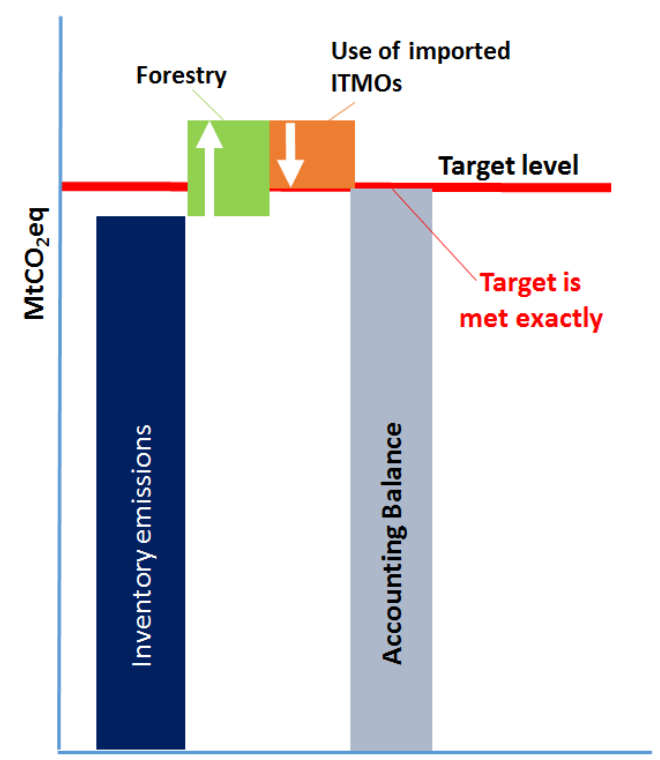

21. The concept of an accounting balance could also be useful when tracking progress in implementation of an NDC, during each biennial communication under the Article 13 Transparency Framework. For Parties that have a multi-year NDC target (i.e. a carbon budget across multiple years), providing an interim accounting balance in each communication would be one way to track the current status of trends in emissions covered by the NDC target ${ }^{7}$. An alternative (or complementary) way for Parties with multi-year NDCs to track progress would be to provide projections of the target/period outcomes in each biennial communication, based on latest information. For Parties with a single-year target, "accounting for" the target in a quantitative sense would occur after the target year, but an interim "tracking balance" (calculated in the same way as an accounting balance) could still be provided in each biennial communication. This would provide a snapshot of how emissions in sectors/gases covered by the NDC target are trending after ITMO use and land sector emissions are taken into account. This could be a transparent means of providing quantitative information to track progress made toward achieving the NDC target. Emissions projections would provide additional information on expected target-year outcomes, but are likely to be challenging for some developing countries.

22. Some NDC targets are quantified in metrics other than GHGs (type G of Table 2), or are more difficult to quantify precisely and would use other indicators of progress and achievement (type $\mathrm{C}$ and $\mathrm{H}$ ). As indicated previously, in submissions no Parties suggested "conversion" of these types of NDC targets into GHG emissions targets, so it seems likely that such targets would be assessed in the same basis that they are communicated (e.g. a target for installation for solar energy would be assessed in terms of the MW installed or GWh generated). A question for Parties will be whether to provide explicit accounting guidance for these types of targets, or to treat them on a case-by-case basis. The direction provided in Article 4.13 (TACCC, environmental integrity, double

\footnotetext{
${ }^{7}$ While Parties would have inventory data for the land sector, Parties may not have systems in place to report accounted emissions in the land sector annually or biennially.
} 
counting) is specifically for accounting for GHG emissions and removals, so there is little guidance provided by the Paris Agreement and Decisions regarding accounting for nonGHG targets8. As the Paris Agreement encourages a trend toward economy-wide emission reduction or limitation targets for all countries over time (Article 4.4), Parties may wish to focus initial work on accounting guidance primarily on GHG-framed targets (both absolute and referenced to baselines). Accounting guidance for non-GHG framed NDC targets could recommend that Parties with non-GHG NDC targets:

- provide clarity ex ante on what indicators/milestones they will use to assess progress and achievement of the NDC target,

- for methodological consistency, use the same data sources and methodologies for the base year (or reference baseline) as for the target year (1/CP.21 para 31 (b)), and

- provide an estimate the GHG reductions associated with the NDC target, if this is possible given the nature of the NDC target. This would be for information purposes, not to "account for" the target per-se.

23. In developing guidance for accounting, many of the Party submissions referred back to the elements in Article 4.13 of the Paris Agreement, elements in Decision1/CP.21, paragraph 31, and the use of existing approaches established under the Convention (UNFCCC, 2017 ${ }_{[3]}$ ). Many Parties' submissions also stated that guidance for accounting should not alter or undermine the nationally determined nature of Parties' NDCs. Parties diverged in view on the application of accounting between different types of NDCs, and between developed or developing country Parties (e.g. some Parties considered that developed countries should take the lead in applying guidance for accounting, and for developing countries the need for capacity building should be taken into account) (UNFCCC, 2017 [3] $)$.

\footnotetext{
${ }^{8}$ Article 6 guidance, rules, modalities and procedures may need to cover the case where Parties with nonGHG targets (e.g. a renewable energy target) that wish to participate in ITMO trade (framed in $\mathrm{tCO}_{2}$-eq)
} 


\section{Accounting for co-operative approaches}

24. Article 6 of the Paris Agreement provides for voluntary co-operation in the implementation of NDCs, which can result in international transfer of mitigation outcomes. Co-operation involving transfers could occur either through the new mechanism outlined in Article 6.4 (seen by some as a successor to the Kyoto Protocol's Clean Development Mechanism) or directly among Parties via domestically established market mechanisms (crediting systems or linked emissions trading systems) under Article 6.2. Some Parties may also wish to trade directly between NDC targets using Article 6.2, i.e. if one Party has over-achieved, it may wish to trade with another Party that is short of its target.

25. Article 6.2 refers to guidance that would support Parties in their obligation to "apply robust accounting, to ensure, inter alia, the avoidance of double counting" when "engaging in co-operative approaches that involve the use of internationally transferred mitigation outcomes". Rules, modalities and procedures for the Article 6.4 mechanism are also to be developed. This guidance is being developed by SBSTA, under a separate process to the more general accounting guidelines corresponding to Article 4.13.

26. Previous CCXG work has explored how market mechanisms might function and be accounted for against diverse national UNFCCC target types (Prag et al., 2011 $1_{[10]}$; Prag, Hood and Barata, 2013 $3_{[1]}$; Hood, Briner and Rocha, 2014[2]; OECD/IEA, 2016 ${ }_{[11]}$ ). There are two major challenges. First, the diversity of NDC target types when compared to the Kyoto Protocol's uniform multi-year carbon budgets will need to be addressed. Single-year targets are a particular challenge: crediting and emissions trading systems operate across multiple years (with banking of units allowed for use in future time periods), so specific guidance may be needed on how to account for ITMO use toward single-year NDC targets with environmental integrity. This is an area where further analytical work to define options would be useful. The second new challenge is that developing countries hosting emission-reduction projects generating ITMOs (e.g. a crediting mechanism, or the new Article 6.4 mechanism) now generally have their own NDC GHG targets under the Paris Agreement. This raises need to avoid double counting (Article 4.13, 6.2 and 6.5), that is, that emission reductions do not count toward both the NDC of the host country and the ITMO buyer's NDC target. New market mechanisms may involve the sharing of benefits (e.g. issued units) between the host country and buyer - in this case it is still necessary to have clarity on which Party is counting which portion of the reductions achieved toward their NDC.

27. Negotiators are at the early stages of developing guidance requested in Article 6.2, and the rules, modalities and procedures for Article 6.4. A number of issues have been identified for further discussion, to underpin robust accounting for both Article 6.2 and 6.4, inter alia:

- To properly account for trade across multiple years (whether the NDC target is for a single year or not), what information would need to be reported (and reviewed)? This could include: 
o An inventory time series, so ITMO trading across time can be referenced to annual emissions.

o Information on issuance, transfers, holdings and retirements/use of credit and ETS units, and Party-to-Party transfers.

o Clarification of the scope of the NDC target.

o Information demonstrating the environmental integrity of domestic market mechanisms and their registry systems.

- How can participating Parties move toward a common definition of a "tonne $\mathrm{CO}_{2}$ eq" (i.e. use of common IPCC methodologies and global warming potentials for inventory reporting, accounting purposes, and for ITMO issuance)?

- How will the mechanics of "corresponding adjustment" to avoid double counting work for Parties with various types of NDC targets? For example how can double counting be addressed in the case where a Party does not have a GHG NDC target, rather an NDC expressed in non-GHG metrics or for specific policies and measures?

- Will guidance on accounting for ITMOs focus only to trade of ITMOs quantified in terms of GHGs (e.g. $\mathrm{tCO}_{2}$-eq)?

- What principles/guidance would be appropriate regarding nationally-governed mechanisms and their unit registries, to ensure environmental integrity and no double counting within the trading systems themselves?

28. If the eventual NDC target accounting procedures are complex, this could reduce the number of developing countries able to participate in use of co-operative approaches, either through Article 6.2 or 6.4. A major challenge in developing the Article 6 accounting guidance will therefore be to strike the appropriate balance between respecting the nationally-determined nature of NDCs, and maintaining environmental integrity by having the most robust accounting possible.

29. The Article 6 guidance will also need to mesh well with the general NDC accounting guidance being developed for Article 4.13, so that the approaches are complementary, even if they apply with different timing: the Article 6 guidance is to apply to the first NDCs. 


\section{Accounting for the land sector}

30. Accounting for the land sector poses specific challenges due to its unique attributes. The complex nature of the land sector includes: difficulties distinguishing between anthropogenic and natural emissions and removals, the role of management practices (which determine the age-class structure of forests) made prior to the start of the NDC target implementation period that can impact emissions and removals into future time periods, and the need to include sinks as well as sources of emissions. Natural disturbances such as wild forest fires and human activities can potentially reverse emission removals; all of which significantly impacts accounting for emissions and removals from forests. There also tends to be relatively high uncertainties associated with estimating emissions and removals in the land sector for both developed and developing countries $^{9}$ (Prag, Hood and Barata, 2013 [1] ; Briner and Konrad, 2014 [12] ).

31. Existing methodological and accounting approaches under the UNFCCC, the Kyoto Protocol and the REDD+ framework provide a starting point for land sector accounting under the Paris Agreement. Discussions on accounting for emissions and removals from the land sector have often focused on two distinctions. The first is between using a "land-based" or an "activity-based" accounting approach.

- A "land-based" approach estimates the changes in carbon stock in a land area, according to the IPCC land classification system. Default methodologies from the IPCC are applied to estimate emissions for each type of land. This approach is used by Parties in reporting national GHG inventories under the UNFCCC.

- An "activity-based" accounting approach estimates the changes in carbon stock according to the dominant activity conducted on a particular unit of land, and is used in reporting for land use, land-use change and forestry (LULUCF) activities under the Kyoto Protocol. The intention of activity-based approach is to highlight the impact of anthropogenic emissions through selected activities, however it creates problems in comparability as reporting of some activities is voluntary.

32. Both "land-based" and "activity-based" accounting approaches estimate humaninduced net emissions and removals from the land sector; and both approaches can be applied to exclude either some land areas or activity types (Prag, Hood and Barata, $\left.2013_{[1]}\right)$. The different approaches can result in different estimates of emissions and removals from the land sector. This can impact a Party's overall progress in achieving mitigation targets and their headline numbers.

\footnotetext{
${ }^{9}$ As an indication, uncertainty calculations are conducted for Annex I country GHG inventories. For New Zealand's 2014 GHG inventory (with 2012 data), the combined uncertainty for $\mathrm{CO}_{2}$ emissions from liquid fuels was $3 \%$ compared to the uncertainty for $\mathrm{CH}_{4}$ emissions from enteric fermentation (16\%) $\mathrm{CH}_{4}$ emissions from manure management (30\%), $\mathrm{CO}_{2}$ emissions from forest land (54\%), $\mathrm{N}_{2} \mathrm{O}$ emissions from agricultural soils (74\%), and $\mathrm{N}_{2} \mathrm{O}$ emissions from manure management (up to 100\%) (New Zealand Government, 2014 ${ }_{[13]}$ )
} 
33. The second distinction relates to approaches for defining the baseline for accounting. As most forestry-based activities have a long time-scale, accounting approaches can be used to smooth out the time lag between emissions and removals from historical decisions and fluctuations from events such forest fires, and from the current mitigation goal and time period. Three main accounting methodologies have been used under the UNFCCC (Prag, Hood and Barata, 2013 ${ }_{[1]}$ ):

- "Net-net” approach: net emissions (emissions minus removals) in the target period are used to compare with net emissions in a base year or period. This approach creates a signal for mitigation relative to historical emissions;

- "Gross-net" approach: net emissions in the target period are estimated without reference to a base year or historical period.

- "Forward-looking baseline" or "reference level": net emissions in the target period are compared with an ex ante estimation of net BAU emissions for the same period. This approach is used in the Kyoto Protocol second commitment period for forest management, and in the REDD+ framework. It also creates a signal for changes in land-use management that reduce emissions relative to BAU and takes out the anticipated non-anthropogenic emissions and removals from accounting.

34. Several Parties have specified land sector accounting approaches in their NDCs. For example; Australia and the United States indicated accounting based on UNFCCC inventory reporting categories using a net-net approach, New Zealand indicated using Kyoto Protocol accounting approaches and Brazil specified using an inventory based approach. Many other Parties have also included the land sector in their NDCs, particularly forestry, but do not specify an accounting methodology.

35. If Parties continue to use a variety of accounting approaches for the land sector, this will make comparability more challenging. Hood, Briner and Rocha (2014) explored options for moving toward a common accounting approach for all Parties, for example, a flexible reference level approach. Flexibility for Parties to define baselines within such a common approach, or to use different approaches, may help to avoid perverse incentives in the sector (for example, encouraging deforestation or unsustainable forestry management practices) for some/all activities and/or land uses (Prag, Hood and Barata, $\left.2013_{[1]}\right)$. If working toward a common approach is not feasible, Hood Briner and Rocha also looked at the option of agreeing common principles for land sector accounting, while allowing Parties to continue to adopt various approaches. Such principles could be more specific - for example relating to construction of reference baselines - or more general, aiming to guide Parties in selecting and explaining their accounting approach. This would provide Parties with more flexibility, but less specific guidance. A question for Parties in this case would be whether the guidance would endorse particular accounting approaches, or leave it to Parties to interpret the principles for themselves. In this latter case, in their biennial communications Parties would need to transparently document the approach they are following for the purposes of technical expert review.

36. Because of the long-time frames associated with changes in the land sector (for example forest planting and harvesting cycles of several decades), one the TACCC elements - consistency - is particularly relevant to land sector accounting. Changing the accounting approach between successive NDC cycles could significantly impact the resulting emissions and removals calculated. Furthermore, as part of good practice, Parties are allowed (and encouraged) to make recalculations to improve estimates of 
emissions and removals in GHG inventories. If a Party changes or improves its data or methodology for a certain year, it will need to make recalculations for that entire period (from the starting year), using the updated data and/or methodology. This can significantly impact reported emissions and removals from the land sector, and change overall the emissions levels within an NDC cycle.

37. A number of Parties have also specifically mentioned accounting for emissions from harvested wood products (HWP) in their NDCs. HWP refers to the carbon stored in wood products that is released during the life cycle of a product (harvesting, manufacture and disposal). Parties must account for HWP under the second commitment of the Kyoto Protocol (Decision 2/CMP.7), however may elect to use one of several approaches identified by the IPCC. In its submission, the European Union suggested that agreeing a unified approach for HWP reporting is feasible, and would increase consistency and comparability, as well as ensure avoidance of omissions and double counting in HWP reporting (UNFCCC, 2017 $[3]$ )

\section{Application of accounting guidance within the NDC cycle}

38. Under the Paris Agreement, Parties would "account for" their NDC targets after the end of the target/year period, to assess actual achievement compared to the target. The primary function of the accounting guidance would be to support this process of accounting for the NDC target ex-post.

39. There will be a time-lag for some information needed for accounting. For example, information in a developed country Party's greenhouse gas inventory is two years behind the year it is reported due to time needed for data collection. For developing country Parties, this time-lag can currently be up to four years ${ }^{10}$. The review process (Article 13.11) for inventory submissions would add further time. Inventory results for the target year/period may therefore not be known until a few years after the end of the target year/period (Figure 3).

40. The Paris Agreement does not include provisions that oblige Parties to meet their NDC GHG targets exactly. However, many Parties will likely wish to do so. As the target year/period will have already passed when inventory information is known, further domestic actions will not affect the total, but Parties could potentially use ITMO transfers (ex post) to achieve their NDC target exactly. Some additional time would be needed after inventory results are reviewed in order to make these ITMO transactions. In the Kyoto Protocol, a "true up period" is provided after the end of each commitment period, to allow time for inventories to be reviewed and finalised and then final unit transactions

\footnotetext{
${ }^{10}$ In practise the delay is currently longer, as biennial update reports have not been submitted by
} most developing countries. 
to be made. For the Kyoto Protocol's first commitment period, the true-up period ended nearly three years after the end of the commitment period ${ }^{11}$.

41. While the main purpose of accounting guidance would be to underpin accounting for the NDC target ex post, the guidance could also be very useful to Parties at earlier stages in the NDC cycle:

- At the time of NDC communication. Understanding how NDC targets will be assessed allows Parties to understand the ambition of NDCs and to formulate them appropriately. Where there is not specific elements of accounting guidance applicable to a particular NDC target type, Parties would need to report information regarding how the NDC will be tracked and assessed as part of information to facilitate transparency, clarity and understanding.

- During implementation of an NDC, when tracking progress toward the NDC target in each biennial communication. Parties could report an accounting/tracking balance to show progress (see Section 2 above), and/or could use the accounting guidelines in providing a projection of target year/period achievement. As well as helping Parties understand progress, this information could also help the facilitative implementation committee under Article 15 understand whether Parties are "on track" or may need facilitation.

Figure 3: Use of accounting guidance at various stages in the first NDC cycle

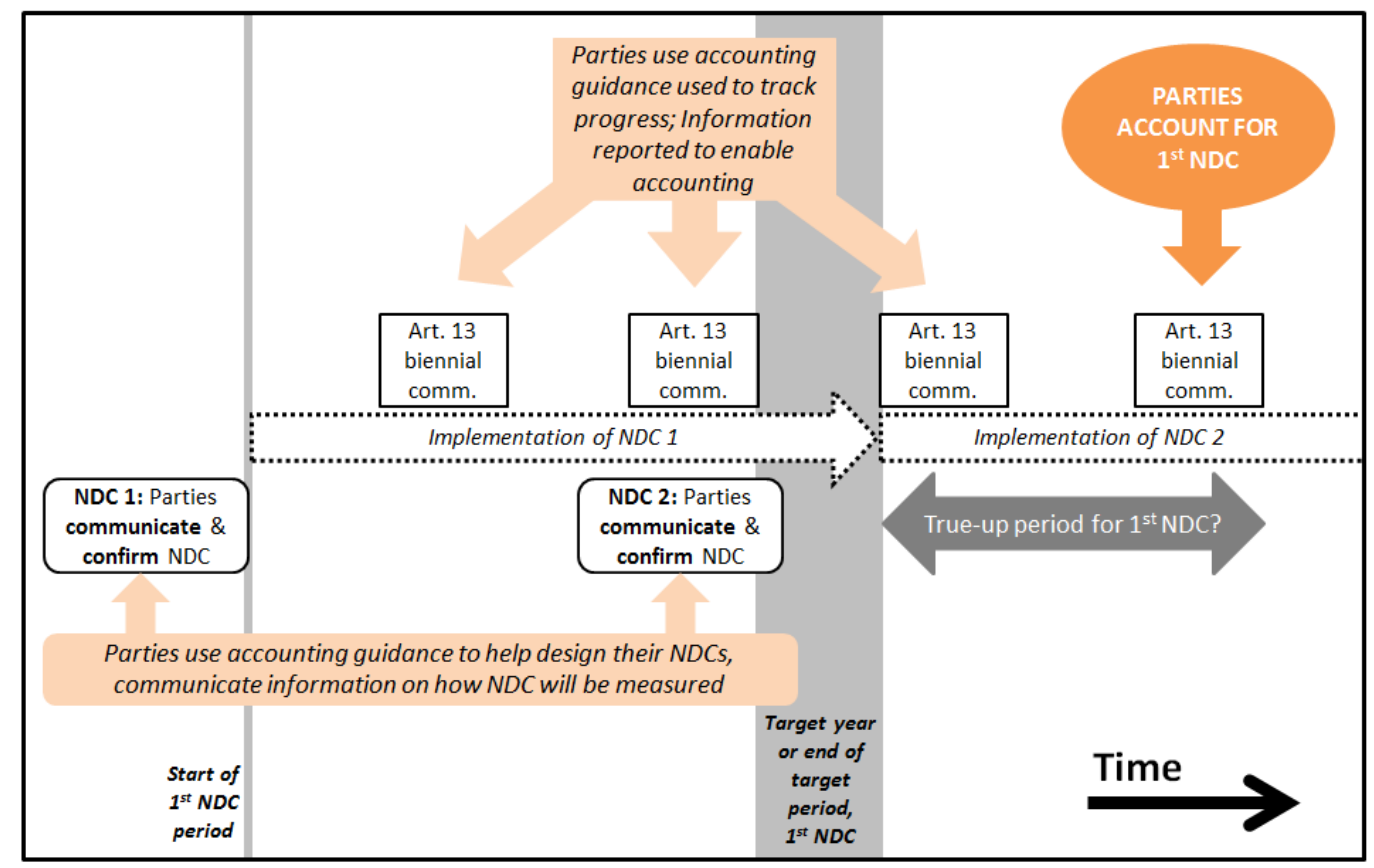

42. Many Party submissions discussed the link between accounting and information necessary for clarity, transparency and understanding within the NDC commitment cycle, while highlighting the distinct timing for information for both elements. Across the

\footnotetext{
${ }^{11}$ The true-up period ended on 18 November 2015, following the end of the first commitment period on 31 December 2012.
} 
submissions, there is not yet convergence on whether the phrase "account for" applies only to the final ex-post assessment of NDC achievement, or whether it also includes the earlier stages in the NDC cycle where accounting guidance would be used. Some submissions (Australia, Canada and New Zealand (UNFCCC, 2017[3])) explicitly identified three distinct stages in tracking progress within an NDC commitment cycle: a) at the start or prior to implementation of an NDC; b) on a regular basis during NDC implementation, and c) at the end of the implementation period, or when data on emissions removals and use of ITMOs becomes available or the next NDC cycle.

43. Tables 3 provides three examples of how and when elements of accounting guidance could be applicable for three NDC target types, which are chosen to illustrate the diversity of actions taken at the communication/ confirmation of the NDC, during implementation of the NDC to track progress and after the target year/period.

Table 3: Potential uses of accounting guidance by Parties for three example NDC target types

\begin{tabular}{|c|c|c|c|}
\hline \multirow[b]{2}{*}{ Type of NDC } & \multicolumn{3}{|c|}{ Potential use of accounting guidance } \\
\hline & $\begin{array}{l}\text { Communication/ confirmation of the } \\
\text { NDC }\end{array}$ & Tracking progress & After the target year/period \\
\hline $\begin{array}{l}\text { Type A: } \\
\text { Economy-wide } \\
\text { absolute emission } \\
\text { reduction target } \\
\text { (tCO} \text {-eq) } \\
\text { e.g. "reduce } \\
\text { emissions by } 40 \% \text { by } \\
2030 \text { compared to } \\
2000 \text { levels" }\end{array}$ & $\begin{array}{l}\text { - Formulation of NDC (e.g. } \\
\text { choice of metrics, LULUCF } \\
\text { and ITMOs accounting). } \\
\text { - Communication of information } \\
\text { to underpin accounting } \\
\text { (timeframes, coverage, } \\
\text { methodologies e.g. GWPs } \\
\text { used) } \\
\text { - Calculating projections for the } \\
\text { target year/period. }\end{array}$ & $\begin{array}{l}\text { - Calculation of current } \\
\text { accounting balance / tracking } \\
\text { balance as a snapshot of } \\
\text { progress. } \\
\text { - Calculation of projections for } \\
\text { the target year/period. }\end{array}$ & $\begin{array}{l}\text { - Calculating accounting balance, } \\
\text { and compare with the NDC target } \\
\text { level. } \\
\text { - Calculating final NDC } \\
\text { achievement after true-up if } \\
\text { ITMO transfers are used (for both } \\
\text { transferring and acquiring } \\
\text { Parties) }\end{array}$ \\
\hline $\begin{array}{l}\text { Type D } 13 \\
\text { Economy-wide goal } \\
\text { relative to a BAU } \\
\text { baseline } \\
\text { e.g. "reduce } \\
\text { emissions } 30 \% \\
\text { below BAU levels by } \\
2030 \text { " }\end{array}$ & $\begin{array}{l}\text { As for Type A, plus: } \\
\text { - Calculating estimate of BAU baseline } \\
\text { and target year emissions, including } \\
\text { explanation on data used, methodology } \\
\text { and assumptions for calculating } \\
\text { baselines. } \\
\text { - Indicating process for revising the } \\
\text { target. }\end{array}$ & $\begin{array}{l}\text { As for Type A, plus: } \\
\text { - If necessary updating baseline, } \\
\text { using same methodology and } \\
\text { data sources as used to } \\
\text { communicate NDC. }\end{array}$ & $\begin{array}{l}\text { As for Type A, plus: } \\
\text { - Calculating final NDC target } \\
\text { level, using same methodology } \\
\text { and data sources as used to } \\
\text { communicate and track the NDC } \\
\text { target. }\end{array}$ \\
\hline $\begin{array}{l}\text { Type G: } \\
\text { Non-GHG target, } \\
\text { renewable energy } \\
\text { e.g. " } 50 \% \text { renewable } \\
\text { electricity by } 2030 \text { " }\end{array}$ & $\begin{array}{l}\text { - Defining indicators and milestones by } \\
\text { which target will be tracked and } \\
\text { assessed } \\
\text { - Communication of information to } \\
\text { underpin accounting (clear definition of } \\
\text { target, timeframe, etc.). } \\
\text { - Calculating estimates/projections of } \\
\text { resulting emission reductions. }\end{array}$ & $\begin{array}{l}\text { - Communicating progress in } \\
\text { terms of specified indicators, as } \\
\text { well as any changes to } \\
\text { projections and up-front } \\
\text { information reported. }\end{array}$ & $\begin{array}{l}\text { - Calculating target year } \\
\text { achievement and comparison } \\
\text { with target, using the indicators } \\
\text { communicated with the NDC. } \\
\text { - Estimating associated emission } \\
\text { reductions. }\end{array}$ \\
\hline
\end{tabular}

12 Briner and Moarif (2016) provide more details on the information that should be communicated at each stage in the NDC cycle.

${ }^{13}$ For sectoral goals to reduce emissions compared to BAU levels (Type E) there would also need to be clarification of the scope of the target at the time the NDC is communicated. 


\section{Conclusions and issues for further discussion}

44. The quest to develop guidance for accounting for NDC targets under the Paris Agreement does not start with a blank sheet of paper: there are multiple experiences to draw from including existing IPCC methodologies, UNFCCC accounting provisions (including REDD+), and the Kyoto Protocol's accounting framework. At the same time, the diverse spectrum of NDCs that have been communicated (including targets for a single year, rather than multi-year periods), and the wide range of developed and developing country capacities to implement accounting raise new challenges. Accounting guidance could, among other things, specify the process for creating an "accounting balance" to calculate how inventory emissions should be compared to the target level, after accounting for ITMOs and the land sector, and a similar "tracking balance" to track progress toward single-year targets.

45. Discussions at the CCXG Global Forum in September 2017 highlighted two important over-arching tensions confronting negotiators. First, there is a risk that very accurate, precise accounting guidance could become very complex, which could impede universal participation in the Agreement unless there is significant capacity-raising. This concern is particularly acute in with respect to accounting for ITMOs under Article 6: Parties will need to strike the appropriate balance between broad participation, and maintaining environmental integrity by having the most robust accounting possible. A second tension relates to the need for continuous improvement in methodologies and processes used (for example, countries progressively moving to more recent or higher-tier GHG inventory methodologies and systems), set against the concern that this could cause NDC targets to be updated frequently and/or significantly, potentially causing confusion regarding the meaning of NDC targets and whether they have been achieved.

46. Parties are at the preliminary stages of developing guidance to account for mitigation targets in NDCs. Although a number of key issues warrant further discussion, some starting questions include:

- What is the relationship between "accounting” and "tracking progress"? Could for example accounting be limited to quantitative assessments of progress toward and achievement of a target?

- To what degree can the accounting guidance be based on general principles for all NDC target types, and where would specific elements of guidance applicable only to certain NDC types be useful?

- What are the implications for review of accounting information if guidance is too generic?

- When should guidance on accounting be applied - before, during and / or after implementation of NDCs?

- What are the practical implications of accounting for NDC targets that are for a single year only, compared to those that are for a multi-year period? 
- How can Parties ensure that accounting guidance being developed under Article 6 for ITMOs is consistent with general accounting guidance, given that these are being developed under separate processes (and potentially to different timelines)?

- Is it feasible to work toward a common accounting framework for the land sector? If not, could principles for land sector accounting be agreed, and/or a list of accepted methodologies or good practice guidelines? 


\section{References}

Briner, G. and S. Konrad (2014), "Planting the Foundations of a Post-2020 Land Sector

Reporting and Accounting Framework”, OECD/IEA Climate Change Expert Group Papers, Vol. No. 2014/06, http://dx.doi.org/10.1787/5js1qf2p7pzw-en.

Briner, G. and S. Moarif (2016), “Unpacking Provisions Related to Transparency of Mitigation and Support in the Paris Agreement”, OECD/IEA Climate Change Expert Group Papers, Vol. No. 2016/02, http://dx.doi.org/10.1787/5jlww004n6nq-en.

Hood, C., G. Briner and M. Rocha (2014), "GHG or not GHG: Accounting for Diverse Mitigation Contributions in the Post-2020 Climate Framework", OECD/IEA Climate Change Expert Group Papers, Vol. No.2014/02, http://dx.doi.org/10.1787/5js1qf652kd3-en.

IPCC (2006), 2006 IPCC Guidelines for National Greenhouse Gas Inventories.

Moarif, S. (2017), "Information needed to facilitate the clarity, transparency and understanding of mitigation contributions”, OECD/IEA Climate Change Expert Group Papers, Vol. No. 2017(1).

New Zealand Government (2014), New Zealand's Greenhouse Gas Inventory 1990-2012, http://www.mfe.govt.nz/publications/climate-change/new-zealands-greenhouse-gasinventory-1990\%E2\%80\%932012.

OECD/IEA (2016), Joint submission by the OECD and IEA to the UNFCCC on "Views on guidance on co-operative approaches referred to in Article 6, paragraph 2 of the Paris Agreement”, https://www.oecd.org/env/cc/CCXG-Submission-Art6-final.pdf.

Prag, A. et al. (2011), "Tracking and Trading: Expanding on Options for International Greenhouse Gas Unit Accounting After 2012”, OECD/IEA Climate Change Expert Group Papers, Vol. No. 2011/05, http://dx.doi.org/10.1787/5k44xwtzm1zw-en.

Prag, A., C. Hood and P. Barata (2013), "Made to Measure: Options for Emissions Accounting under the UNFCCC”, OECD/IEA Climate Change Expert Group Papers, Vol. No.2013/01, http://dx.doi.org/10.1787/5jzbb2tp8ptg-en.

SEI (2016), Ensuring the environmental integrity of market mechanisms under the Paris Agreement, http://sei-us.org/Publications_PDF/SEI-PB-2016-Market-mechanisms-ParisAgreement.pdf.

UNFCCC (2015a), Adoption of the Paris Agreement, Decision 1/CP.21, UN Secretariat, http://unfccc.int/resource/docs/2015/cop21/eng/109r01.pdf.

UNFCCC (2015b), Report of the Ad Hoc Working Group on the Durban Platform for Enhanced Action Synthesis report on the aggregate effect of the intended nationally determined contributions, UN Secretariat, http://unfccc.int/resource/docs/2015/cop21/eng/07.pdf..

UNFCCC (2017), Compiled Submissions at APA 1-3. Item 3: Further guidance in relation to the mitigation section of decision 1/CP.21, UN Secretariat.

Vallejo, L. (2017), Enhancing mitigation and finance reporting, OECD/IEA Climate Change Expert Group Papers, http://dx.doi.org/10.1787/2227779X. 


\title{
www.oecd.org/environment/cc/ccxg.htm
}

\author{
www.iea.org
}

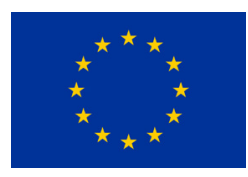

With the financial assistance of the European Union 